conflagration has not reached stand in the clearest relief as they are seen for probably the last time; but in a dozen spots, at both ares of the bridges, sheets of flame and awful volumes of smoke sides of the bridges, shitively obscure the light of the sun. I am rise to the sky and positive the Trocadéro. Close and immediately making these notes on the Trides, with its gilded dome shining brightly as ever."

Another as follows :- "As I drive along the green margin of the placid Seine to St. Denis, the spectacle which the capital the placid souses the presents is one never will not refuse his beams spite of the deeds sun still smiles; he will not refuse his the sunbeams struggle and which they illumine. But and folds and pillars of dense smoke ; not one or two, but I reckon them on my fingers till 1 lose the not one

Twenty-four hours later, the change has come. "The rain is now falling heavily, has been falling heavily all day, and may do something for burning Paris. The sound of artillery has died away; " and from another writer :-"

ver Paris and rain is constanty farked that rain generally follows

I believe it has often been this case there is an almost unexa heavy cannonading, but in this case there is an almost unexampled artillery fire and tremendous conflagration at the same time, accompanied by a sudden and violent change in the atmospheric conditions. From where I am writing we noticed a remarkable change on Thursday morning, and about 2 P.M., after markable chang and oppression, a rain of a tropical character intense closeness and oppression, On many occasions in Queens. set in for twelve hours or more. Of drought, after extensive grass land, I noticed that in seasons of drought, after extensive grass fires, causing intense heat, heavy thunderstorms generally followed.

Rodborough Lodge, Stroud, May 27

\section{Alleged Daylight Auroras}

SEVERAt letters having appeared in recent numbers of SEving what the writers consider to lave been unNATURE, giving what the wrisile in the daytime, you will, I doubtcd instances of aurora visible why I still adhere to the hope, allow me to state the reasons why 1 still adhere to the views expressed in my former communication on this subject. And, first of all, I must beg your correspondent Mr. Jeremiah not to think me uncourteous if I dismiss at once, as unworthy serious criticism, the cases which he has dug out of monkish chronicles. It is likely enough that some of these old records may be imaginative descriptions of nocturnal auroras, and as such they are not without interest, but I can such they are not withos a point of nicety.

competent witnesses on a po adduced by the same correspondent A more modern instance adduced for May 4, under the title will be found at p. 7 of NATURE for May 4, under the thitle "Aurora Borealis, seen in the daytime at Canonded between the case it is difficult to know what relation is intended between the title and the account which follows. The account describes the clearing off of the clouds in a mass from the north-west, with the production of an "azure arch," the centre of which "reached an elevation of $20^{\circ}$." If I reply to this that the clearing off of clouds is not an aurora, even though they clear off in a compact body from the north-west, leaving an azure arch ' I strongly met by the rejoinder that nobody said confused idea that he was suspect that the writer had some confused idea that he wras describing an auroral arch, and I am certain that nine out of ten readers, misled by the heading, would take the same view. Stripped of the cloud-phenomena, all that remains of the Canonmills aurora is the appearance of some "very faint perpendicilar streaks of a sort of milky light, "which could be tremely slight and evanethe segment of blue sky, but were extreme observer regarded scent." Considering the probability that the observer regarded the cloud-arch as auroral, which it ce likely to be biassed by that sidering how his judgment would be likely to be biassed by that idea in the interpretation of "extremely slight and evanescent" appearances, $I$ th

ticularly weak.

In NATURE for Dec. 8, 1870, Mr. Cubitt describes and figures a double auroral arc which $25^{\circ}$ above the horizon, and almost due October. It was "some 25 expressed a doubt of the correctness east." In my first letter I expressed a doubt of the correctness of this observation on the ground that auroral arcs are not seen in the east. My criticism has since been challenged on two distinct issues. Mr. Jeremiah insists that an auroral arc may

* Nature, vol, iii. p. I26. extend towards the east, and that what $\mathrm{Mr}$. Cubitt saw may have been the eastern extremity of a northern arc. A reference to Mr. Cubitt's letter and illustration will show at once that if what he saw was any part of an arc, it was the apex and not what tremity. But another correspondent, Mr. Reeks, in N NTUR of Dec. 29, 1870, in criticising my remark, makes a statement which is more difficult to answer. He affirms positively that in Newfoundland he has many times seen the arch nearly due in that is, as he explains, with " the extremities pointing N.N.W. and S.S.E." I would suggest, however, in reply to this statement, that in an extensive auroral display there may be fictitious arches, produced by the accidental correspondence of streamers on either side of the "cupola." An arch of this kind may easily extend from N.N.W. to S.S.E., spanning the entire heavens. It is essentially different from the true auroral arc, which, until much stronger evidence to the contrary is adduced, I shall still believe to be invariably transverse to the magnetic meridian. Obviously, Mr. Cubitt's arc was not of the kind that Mr. Reeks describes.

I pass on to a record of daylight aurora, which, more than any other that I have seen, demands a careful investigation. I refer to "An Account of an Aurora Borealis seen in full Sunshine, by the Rev. Henry Ussher, D.D.," said to be taken from the Transactions of the Royal Irish Academy for 1788 , and quoted by the Rev. T. W. Webb in Nature for May II. Dr. Ussher's account, it must be admitted, is most particular and complete. He describes "whitish rays ascending from every part of the horizon, all tending to the pole of the dipping needle, where, at their union, they formed a small thin and white canopy similar to the luminous one exhibited by an aurora at night." Nothing can be more precise. But is it not also a trifle too wonderful? Surely, if any part of an aurora is to be seen by daylight, it must be just one here and there of the most vivid beams. That the whole phenomenon should be visible at noon-day in all its completeness, just as at night, even to the faint extremities of the streamers in the magnetic zenith, is to my mind so entirely inconceivable that not even the authority of a doctor of divinity can command my faith in it. I can much more easily believe that the sky presented a remarkably symmetrical arrangement of radiating cirri, and that the observer, impressed by the recollection of the aurora of the previous evening, persuaded himself that the "rays coruscated from the horizon to their point of union." The confirmation by "three different people" is of little value unless their observations were independent.

To those who have no clear conception of the difference be tween cirrus and aurora, the foregoing arguments will be meaningless. Some persons write very loosely of "luminous cirri," and I have even seen described the transformation of cirrus cloud into aurora as it grew dark. I believe that there is no connection between the two phenomena beyond an occasional and purely accidental similarity of form, and that when the two co-exist, the cirrus, instead of being the seat of the aurora or deriving luminosity from it, only serves to obscure its brightness, and, if dense enough, may appear in the form of dark bands across the auroral light, the latter being, as I conceive, at a very much greater elevation.

I adverted in my former letter to the argument that may be drawn from the non-visibility in the day-time of other lights comparable with the aurora, and I will only now add the following suggestion. If the auroras that occur in this country are occasionally visible in daylight, it might be supposed that the much grander displays of the Arctic regions would be habitually visible in daylight. But is the fact so ? Clifton, May 23

George F, Burder

\section{Aurora Australis}

Traversing the Indian Ocean $44^{\circ} \mathrm{S} .65^{\circ} \mathrm{E}$., I observed, September 24 th, I870, $4 \mathrm{~h}$. till $\mathrm{r} 3 \mathrm{~h}$. Greenwich time, a south polar light of great intensity and splendour. After my arrival at Manado (Celebes) I was just writing a few lines about it for the readers of NATURE, with the purpose of knowing whether at the same time an aurora, or at least disturbance of the magnetic needle, had been observed on the northern hemisphere, when I saw in NATURE (Nos. 49, 50, and 5I, 1870), several interesting descriptions of aurora borealis observed September 24 in England, \&c. I am not aware whether many observations of southern polar lights have been recorded, but I remember that those which Cook described in the year $\mathbf{1} 773$ were coincident with aurora borealis observed in Friesland, and others observed in 17,83 